\title{
O pensamento sistêmico aplicado à advocacia: um caminho para a sua ressignificação
}

\author{
El pensamiento sistémico aplicado a la abogacía: um camino hacia su \\ resignificación
}

Systemic thinking applied to advocacy: a path to its re-signification

Carolina Portella Pellegrini ${ }^{1}$

\begin{abstract}
Resumo
O paradigma sistêmico aplicado ao Direito remete um novo olhar deste sobre si, sobre a sua forma de realizar ciência, sobretudo no que tange a transformação da maneira tradicional com que se conduz e trabalha o fenômeno que é a força motriz para o exercício de qualquer profissão na área jurídica: o conflito. Passa a compreendê-lo como um fenômeno que desperta diversos pontos de vista e que, por isso, seria necessário retirar o enfoque sobre a culpa para efetivamente buscar (re)equilibrar o que está em desarmonia. Dirige-se o olhar para os contextos e para o reconhecimento dos ruídos nas relações. Nesse sentido, a aplicação desse paradigma a advocacia, por meio do modelo de gestão da advocacia sistêmica, pode ser um caminho de materialização de acesso à justiça, de resgate do propósito da advocacia, na mesma medida em que a ressignifica. Por isso, esse artigo objetivou, por meio de pesquisa bibliográfica e observacional, refletir sobre esse momento do Direito e, especialmente, da advocacia. Partindo-se, num primeiro momento, de um panorama acerca do paradigma tradicional da ciência (e do modus operandi da advocacia): cartesiano (positivista). Depois, se expôs o pensamento sistêmico como novo paradigma da ciência. Para, por fim, se sustentar a aplicação do pensamento sistêmico, como ferramenta de materialização do acesso à justiça e de ressignificação da advocacia.
\end{abstract}

Palavras-Chave: paradigma; pensamento sistêmico; advocacia; ressignificação.

\section{Resumen}

El paradigma sistémico aplicado al Derecho remite una nueva mirada de éste sobre sí, sobre su forma de realizar ciencia, sobre todo en lo que se refiere a la transformación de la manera tradicional con que se conduce y trabaja el fenómeno que es la fuerza motriz para el ejercicio de cualquier profesión en el ámbito jurídico: el conflicto. Pasa a comprenderlo como un fenómeno que despierta diversos puntos de vista y que, por eso, sería necesario retirar el enfoque sobre la culpa para efectivamente buscar (re) equilibrar lo que está en desarmonía. Se dirige la mirada hacia los contextos y el reconocimiento de los ruidos en las relaciones. En este sentido, la aplicación de ese paradigma la abogacía, por medio del modelo de gestión de la abogacía sistémica, puede ser un camino de materialización de acceso a la justicia, de rescate del propósito de la abogacía, en la misma medida en que la resignifica. Por eso, ese artículo objetivó, por medio de investigación bibliográfica y observacional, reflexionar sobre ese momento del Derecho y, especialmente, de la abogacía. Partiendo, en un primer momento, de un panorama acerca del paradigma tradicional de la ciencia (y del modus operandi de la abogacía): cartesiano (positivista). Después, se expuso el pensamiento sistémico como nuevo paradigma de la ciencia. Para, por fin, sostener la aplicación del pensamiento sistémico, como herramienta de materialización del acceso a la justicia y de resignificación de la abogacía.

Palabras claves: paradgima; pensamiento sistêmico; abogacía; replanteo.

\section{Abstract}

The systemic paradigm applied to the Law refers a new look of this about itself, about its form of realizing science, especially as it relates to the transformation of the traditional way in which the phenomenon that is the driving force for the exercise of any profession is conducted and worked in the legal area: the conflict. It comes

1 Mestre em Direito e Justiça Social pela Universidade Federal do Rio Grande, RS; Brasil; cacapellegrini@hotmail.com 
to understand it as a phenomenon that arouses different points of view and that, therefore, it would be necessary to withdraw the focus on guilt to effectively seek (re) balance what is in disharmony. It looks at the contexts and the recognition of noises in relationships. In this sense, the application of this paradigm to advocacy, through the model of systemic advocacy management, can be a way to materialize access to justice, to rescue the purpose of advocacy, in the same way that it re-signifies it. Therefore, this article aimed, through bibliographical and observational research, to reflect on this moment of Law, and especially of the law. Starting from the outset, there is a panorama about the traditional paradigm of science (and the modus operandi of advocacy): Cartesian (positivist). Later, systemic thinking was exposed as a new paradigm of science. Finally, to support the application of systemic thinking, as a tool for materializing access to justice and re-signifying advocacy.

Keywords: paradigm; systemic thinking; advocacy; redetermination.

\section{Introdução}

O presente estudo surgiu de um desconforto em relação ao modo de operar dos advogados em sua profissão (tanto no que tange a relação cliente-advogado, quanto aos seus processos, ao sistema judiciário, enfim, em todas as conexões decorrentes dessa profissão), bem como de reflexões sobre a essência da advocacia. De maneira que a partir disso se despertou para o aprofundamento de estudos acerca de outros métodos de soluções de conflitos que não apenas o heterocompositivo e sobre o pensamento sistêmico.

O pensamento sistêmico como novo paradigma da ciência aplicado ao Direito, torna-o, assim como qualquer área de atuação humana em que for aplicado, mais integrado e livre, na medida em que dirige o olhar para os contextos, para os recursos de mudanças e de autonomia. É voltado, conforme Aun (2013, p. 10):

\footnotetext{
Para quem desconfia das certezas do pensamento científico, mas que, ainda assim, quer continuar cientista - radicalmente um novo cientista. Para quem está disposto a fazer a volta autorreflexiva, isto é, para quem está disposto a aplicar a ciência sobre si mesma para questioná-la e reformulá-la a partir dela mesma (AUN, 2013, p. 10).
}

Foi nessa linha de autorreflexão que se passou a pensar acerca da aplicação desse paradigma na advocacia. O modelo de Gestão da Advocacia sistêmica foi introduzido na vida da autora por meio de um curso, criado e idealizado por Marcella Santos. Segundo Santos (2018, n.p), a advocacia sistêmica nada mais é do que o exercício da advocacia sob o paradigma do Pensamento Sistêmico, referindo-se ao despertar de competências transversais pelos advogados, ou seja, habilidades e conhecimentos não específicos do Direito, como relacionais, sensoriais e técnicas.

Significa que "[...] ao desenvolver competências essenciais, o advogado facilita a ampliação de consciência de seus clientes, convidando-os a percepção ou visualização sistêmica dos contextos, relações, padrões, processos e origem do conflito" (SANTOS, 2018, n.p). Nesse sentido, acredita-se que esse modelo de gestão da advocacia pode ser um caminho de materialização do direito de acesso à justiça, na medida em que externa a construção de 
novos olhares para a advocacia, pautados na eficácia e satisfatoriedade no modo como os conflitos são conduzidos e resolvidos. E, principalmente, de alinhamento com o propósito da advocacia, na mesma medida em que a ressignifica.

Logo, pretende-se, por meio de pesquisa bibliográfica, jurisprudencial e até observacional (por meio de cursos, palestras, workshops e etc.) ${ }^{2}$, analisar e refletir sobre esse momento, do Direito e especialmente da advocacia. Justificando-se a relevância do presente artigo no fato de que pesquisa um novo paradigma que visa promover soluções dialogadas, especialmente considerando que está consubstanciada em um senso de não exclusão do Outro e dos contextos, olhando para as conexões. Contudo, em uma conjuntura de relações jurídicas distinta da que comumente se costuma estudar, já que, em geral, os estudos acadêmicos se passam no âmbito do judiciário, relacionados à mediação, a conciliação, a arbitragem, a justiça restaurativa e etc.

De tal modo, se partirá de uma exposição sobre o paradigma tradicional da ciência (e do modus operandi da advocacia): cartesiano (positivista). Depois, será exposto o pensamento sistêmico como novo paradigma da ciência. Para, por fim, se sustentar a aplicação do pensamento sistêmico, como ferramenta para a ressignificação da advocacia.

\section{O paradigma tradicional da ciência (e do modus operandi da advocacia): cartesiano (positivista)}

O vocábulo paradigma pode ser utilizado em diversas acepções - enquanto teoria, enquanto crenças e valores compartilhados, e etc. Para Capra (2014, p. 26) paradigma é "uma constelação de conceitos, valores, percepções e práticas compartilhadas por uma comunidade, formando uma visão particular da realidade que é a base da maneira pela qual a comunidade se organiza".

Portanto, os paradigmas funcionam como filtros que selecionam o que percebemos, reconhecemos e no que cremos. Nesse sentido Vasconcellos (2013, p. 39) bem destaca que: "É muito importante prestar atenção a esse ponto: quando trabalhamos em ciência, nós o fazemos sempre a partir de nossos pressupostos, nossa maneira de ver a natureza, nossa visão do objeto com que trabalhamos". Por isso, segundo essa autora, "para sabermos as coisas que estão sendo vistas, temos que nos perguntar pelos paradigmas daqueles que estão vendo" (VASCONCELLO, 2013, p. 39).

\footnotetext{
2 Há pouco material científico referente a essa temática. Os estudos ainda estão na base do método fenomenológico, sobretudo se se considerar que muitos ainda atrelam a visão sistêmica apenas às constelações familiares, enquanto, em realidade, as constelações são uma das ferramentas do paradigma sistêmico.
} 
Por isso, desde já, se reconhece que os paradigmas nos quais a autora deste artigo se formou são consubstanciados em um viés favorável aos métodos autocompostivos e aos estudos sistêmicos. E, sobretudo, na compreensão de que a relação cliente-advogado em muito perpassa questões jurídicas e que o modus operandi tradicional do modelo de gestão de conflitos não é mais sustentável.

Logo, com o presente estudo se pretende abordar o pensamento sistêmico como uma forma nova de pensar cientificamente, tocando a essa pesquisa, mais especificamente, a aplicação desse paradigma no âmbito da advocacia. Por isso, concorda-se com Vasconcellos (213, p. 50) quando considera que o pensamento sistêmico é o novo paradigma da ciência, ou seja, uma outra forma de ver e pensar o mundo, e, portanto, de lidar com ele, que é bastante diferente da forma tradicional de pensá-lo ou de conhecê-lo cientificamente.

Mas, então, qual seria essa "velha" forma de pensar o mundo? Qual o paradigma até então posto (como se pensava cientificamente até então)? O paradigma tradicional da ciência foi consubstanciado a partir das contribuições de muitos autores, mas, para esse estudo, serão abordados, em especial, as de René Descartes, Isac Newton e Augusto Comte, os quais influenciaram em todos os demais ramos do saber, especialmente o Direito.

Trata-se de paradigma que vem se mantendo através dos séculos até os dias de hoje, fundado basicamente sob as premissas da razão e da objetividade. É uma visão do mundo, e da ciência, extremamente mecanicista - segundo a qual toda a natureza funciona de acordo com leis mecânicas - e reducionista - e tudo no mundo natural pode ser explicado em função dos arranjos e movimentos de suas partes. Isso implica que se poderia ser capaz de compreender todos os aspectos de estruturas complexas reduzindo-as às menores partes que as constituem (CAPRA, 2014, p. 61).

René Descartes, ou Cartesius (seu nome latinizado), é comumente considerado o criador da filosofia moderna. Acreditava que ciência era sinônimo de matemática, baseando a sua concepção de natureza na divisão entre dois domínios independentes e separados: o da mente e o da matéria. E isso implicou na crença de que o mundo era um sistema mecânico, o qual poderia ser objetivamente descrito, retirando-se qualquer carga valorativa e subjetiva dessa descrição.

Mais que isso, ao assumir uma posição dualista no que diz respeito a questão ontológica da relação entre o pensamento e o ser, fracionou oficialmente o mundo em material e espiritual, corpo e mente, nos seres vivos (VASCONCELLOS, 2013, p. 62). Admitia duas substâncias: uma das coisas, cujo atributo é a extensão (res extensa); e a outra do sujeito pensante (ego cogitans), cujo atributo é o pensamento (VASCONCELLOS, 2013, p. 62). 
Portanto, foi no paradigma cartesiano que se dissociou a cultura humanista da cultura científica. Assim, o método de Descartes é analítico, ou seja, compreende que é necessário dividir os pensamentos e problemas em pedaços para arrumá-los em sua ordem cronológica (CAPRA, 2014, p. 48). Nesse sentido, como bem destaca Capra (2014, p. 48):

[...] a ênfase excessiva no método cartesiano levou à fragmentação, que caracteriza tanto o nosso pensamento em geral como as nossas disciplinas acadêmicas, e à difundida atitude do reducionismo da ciência - a crença em que todos os aspectos dos fenômenos complexos podem ser entendidos reduzindo-os às suas menores partes constituintes [...] Em outras palavras, todas as teorias científicas são reducionistas no sentido de que precisam reduzir os fenômenos descritos a um número de características capazes de ser praticamente manejáveis. No entanto, a ciência não precisa ser reducionista no sentido cartesiano de reduzir os fenômenos às suas menores partes constituintes.

E Isaac Newton ratificou os ensinamentos de Descartes, trazendo para o paradigma tradicional a ideia de que o mundo seria como uma máquina, pois "A imagem do mundo como máquina perfeita, que fora introduzida por Descartes, era agora um fato comprovado, e Newton tornou-se o símbolo" (CAPRA, 2014, p. 55). No que tange ao campo do Direito, o paradigma tradicional da ciência foi também muito influenciado pelo filósofo social Augusto Comte, conhecido como o pai do positivismo.

Comte separou as ciências da natureza das ciências do homem. De acordo com Capra (2014, p. 74): "Suas afirmações incluem a insistência em que as ciências sociais deveriam procurar leis gerais para explicar o comportamento humano, uma ênfase na quantificação e a rejeição de explicações dependentes de fenômenos subjetivos, como intenções e propósitos". Por conseguinte, o positivismo exige a objetividade, fundando o conhecimento na coisa e não no homem, daí sua compreensão de necessidade de se afastar juízos e valores.

Desta forma, a tradição jurídica brasileira tem como alicerce o paradigma da lei como fonte primária, fundado nos pilares do racionalismo e do dogmatismo, com predomínio do raciocínio teórico-dedutivo na construção dos seus sistemas jurídicos (BARREIROS, 2011, p. 217). Conforme já se tratou em Pellegrini e Simioni (2015, p. 124): "A herança desse paradigma tradicional para o campo do direito se reflete na sua instrumentalização, bem como no seu apego exacerbado ao formalismo, ao procedimento, visando sempre uma determinada certeza e logicidade".

Assim: "Em nome de uma segurança jurídica que não condiz com a complexidade do direito e das relações do mundo moderno, passa-se a adotar fórmulas gerais e abstratas, na busca de uma epistemologia universal" (PELLEGRINI; SIMIONI, 2015, p. 124). E toda essa objetividade e racionalidade se refletem no modus operandi do advogado. 
De tal forma, dentro desse paradigma, é comum que os advogados adotem, com frequência, as premissas de que: (i) as partes em conflito atuam de forma adversarial e (ii) que os conflitos devem ser resolvidos por aplicação de uma regra geral de direito, o que se faz habitualmente através de um juiz (ALMEIDA; PAIVA, 2016, p. 263). Por conseguinte, formado a atuar conforme o paradigma tradicional, normalmente, trabalha de maneira unilateral, no sentido de analisar e se preocupar apenas com uma das partes (a que representa), acostumando-se a falar pelos seus clientes e se preocupando em resolver apenas a demanda jurídica e não a sociológica dos processos, pois não lhe é dado dar vazão aos sentimentos implícitos as demandas.

Contudo, ironicamente, não raro se deparam com as complexidades e especificidades que quem lida com o ser humano e suas contendas se depara. Nesse sentido, o modo tradicional de lidar com os conflitos, de acordo com o que destaca Silveira (2005, p. 180), empobrece as possibilidades de soluções possíveis, dificultando a relação entre as pessoas envolvidas e, o mais importante, gerando altíssimo custo econômico, afetivo e relacional.

Portanto, sinteticamente, as características do paradigma da ciência tradicional se refletem basicamente em três pressupostos epistemológicos:

A crença na simplicidade do microscópio, ou seja, a crença em que, analisando ou separando em partes o objeto complexo, encontrar-se-á o elemento simples, a substância constituinte, a partícula essencial, mais facilmente compreensível do que o todo complexo.

A crença na estabilidade do mundo, ou seja, a crença em que o mundo é um mundo estável, que já é como é, e de que podemos conhecer os fenômenos determinados e reversíveis que o constituem, para poder prevê-los e controla-los.

A crença na possibilidade da objetividade, ou seja, a crença em que é possível e indispensável sermos objetivos na constituição do conhecimento verdadeiro do mundo, da realidade (VASCONCELLOS, 2013, p. 65-66).

De tal modo, em um paradigma pautado em premissas como essas o saber só pode ter se revelado fragmentado, rompido e insuficiente porque simplifica o complexo, unifica o diverso, desconsidera contextos e preocupa-se apenas em quantificar e não qualificar. Traz toda uma abordagem racional de controle do mundo, preocupando-se com a coerência lógica, eliminando imprecisões, ambiguidades e contradições (VASCONCELLOS, 2013, p.77).

Por isso se constata a incompletude desse paradigma da ciência. Daí a necessidade de repensá-lo, por meio do emergir de um novo paradigma. Capra (2014, p. 25) refere que as mudanças paradigmáticas se dão devido à quebra de continuidade, a rupturas revolucionárias. E o pensamento sistêmico enquanto paradigma social e científico representa essa quebra de continuidade, pois o mundo deixa de ser visto em partes, segmentado e de forma mecanicista, 
para ser analisado como um todo, inter-relacionado, uma rede. São mudanças nas percepções, nas maneiras de pensar e nos valores.

\title{
3. O pensamento sistêmico como novo paradigma da ciência ${ }^{3}$
}

O pensamento sistêmico é uma nova forma de ver a ciência. E não uma nova ciência. Essa é a concepção defendida por Vasconcellos (2013), segundo a qual:

\begin{abstract}
[...] acho importante enfatizar que quando falo de novo paradigma de ciência estou me referindo ao paradigma emergente a partir do século XX, especialmente em sua segunda metade. Ou seja, aos desenvolvimentos científicos que estão ocorrendo a partir da própria ciência tradicional, levando os cientistas a rever seu paradigma de ciência (VASCONCELLOS, 2013, p. 94).
\end{abstract}

São expoentes das teorias sistêmicas clássicas: Alexander Bogdanov (tectologia), Ludwig von Bertalanffy (autor da Teoria Geral dos Sistemas) e Norbert Wiener. De acordo com Capra (2014, p. 93), as primeiras ideais sobre pensamento sistêmico surgiram na Europa durante a década de 1920, sendo que os biólogos foram os primeiros a abordar a temática ao enfatizar a visão dos organismos vivos como totalidades integradas. Após, surgiram contribuições da psicologia da Gestalt e pela nova ciência da ecologia, e, especialmente, pela física quântica.

A palavra sistema, segundo com Capra (2014, p. 94), deriva do grego syn + histanai (“colocar junto"), logo o pensamento sistêmico implica uma mudança de perspectiva das partes para o todo, ou seja, a compreensão de que as partes precisam ser colocadas em um contexto, de modo a estabelecer a natureza das suas relações. Isso quer dizer que o paradigma sistêmico é oposto ao analítico (cartesiano), o qual separa as partes e as considera isoladamente para entendê-la. Portanto, o pensamento sistêmico representa a compreensão de um fenômeno dentro de um contexto que faz parte de um todo maior.

Ademais, o paradigma sistêmico, enquanto ciência, também rompe com o ideário de que o conhecimento científico é algo objetivo e absoluto. E que, por isso, qualquer influência do processo de conhecimento e carga valorativa do pesquisador deve ser afastada. Vislumbrase que há a mudança de uma "ciência objetiva para uma ciência epistêmica, isto é, a epistemologia - o 'método de investigação' - torna-se parte integrante das teorias científicas. Reconhecendo-se que conceitos e teorias são aproximados e limitados, pois não há um conhecimento completo e definitivo (CAPRA, 2014, p. 115/114).

\footnotetext{
${ }^{3}$ Título inspirado na obra de Vasconcellos (2013).
} 
Nesse sentido, é um paradigma alicerçado em premissas como as da complexidade, da instabilidade do mundo, da intersubjetividade, da multidisciplinariedade, de relações, padrões e conexões. Para Vasconcellos (2016, p. 154) nem tudo que se apresenta hoje como pensamento sistêmico é novo-paradigmático. Essa autora concebe como pensamento sistêmico novo-paradigmático um modo de pensar que implica ter assumido os três novos pressupostos que constituem esse 'novo paradigma de ciência': a complexidade, a instabilidade e a intersubjetividade.

Conceber a instabilidade do mundo quer dizer não compreendê-lo como algo fechado. Pelo contrário, encará-lo em transformação contínua, “em processo de tornar-se”. Ao passo que a intersubjetividade denota "o reconhecimento da impossibilidade de um conhecimento objetivo do mundo" (Vasconcellos, 2016, p. 129). Em outras palavras, relaciona-se com a transdisciplinariedade, o reconhecimento de múltiplas verdades e etc.

Portanto, vislumbra-se nesse paradigma uma ampliação de foco, na medida em que passa a se trabalhar o objeto em seu contexto, ambiente e relações envolvidas. Ao passo que olhar para o contexto significa compreender que tudo é conectado, como uma rede e, por isso, único. De tal forma passa-se a estabelecer inter-relações e conexões, pois pelo paradigma sistêmico "não se trata mais de reduzir o complexo ao simples - não reducionismo -, mas de integrar o simples no complexo" (VASCONCELLOS, 2013, p. 113).

Nesse sentido, a complexidade se contrapõe a simplificação do paradigma tradicional. Segundo Vasconcellos (2013, p. 105):

[...] faz pouco tempo que a complexidade deixou de ser uma invocação de dificuldade de compreensão ou de realização, ou uma justificativa da falta de uma teoria ou da insuficiência das explicações, para se tornar uma questão a abordar, um objeto de estudo e de pesquisa sistemática.

Assim, como o pensamento sistêmico é pautado na complexidade de Edgar Morin, pode-se afirmar que está alicerçado no princípio dialógico. Ou seja, permite abordar as contradições e não as exclui, pois "dialógico" quer dizer impossível de chegar-se a uma unificação, a um princípio único, a uma solução monista (VASCONCELLOS, 2013, p. 113). Nesse sentido: “Aplicar esse princípio significa articular, mantendo a dualidade no seio da unidade, sem pretender realizar uma síntese" (VASCONCELLOS, 2013, p. 113).

Então, a dialógica é característica fundamental do pensamento complexo, ou seja, de um pensamento capaz de unir conceitos que tradicionalmente se opõem, considerados racionalmente antagônicos, e que até então se encontravam em compartimentos fechados 
(VASCONCELLOS, 2013, p. 115). Destarte, de forma sucinta, o pensamento sistêmico pode ser entendido da seguinte forma:

Pensamento sistêmico significa uma mudança de percepções de objetos e estruturas materiais para processos e padrões de organização não materiais que representam a própria essência da vida. Também deveríamos acrescentar que a ênfase nas relações, nas qualidades e nos processos não significa que os objetos, as quantidades e as estruturas não são mais importantes. Quando falamos em mudanças de perspectiva, não queremos dizer com isso que o pensamento sistêmico elimina completamente uma perspectiva em favor de outra, mas, em vez disso, que há uma interação complementar entre as duas perspectivas, uma mudança entre figura e fundo (CAPRA, 2014, p. 112).

Logo, é um paradigma que privilegia a integração sem eliminar as diferenças. Por isso, afirma-se que os modelos cartesiano e sistêmico não são excludentes, e sim caminham juntos. Por conseguinte, sustentar o modelo sistêmico é acolher o paradigma cartesiano compreendendo que ele existe e faz parte -, no sentido de ultrapassar aquela visão dual e simplista ao validar a complexidade da vida: “[...] onde só é possível entender os fenômenos dentro de um contexto relacional e dentro de um todo maior" (MADALENO, 2017).

\section{O pensamento sistêmico como ferramenta para a ressignificação da advocacia}

O pensamento sistêmico aplicado ao Direito, coloquialmente chamado de Direito Sistêmico, é a inserção desse novo paradigma da ciência - de mudança de visão de mundo e do fazer ciência - no meio jurídico. Damaris Badalotti (2018, n.p) assim conceitua Direito Sistêmico:

[...] o Direito Sistêmico pode ser compreendido como um ramo da Ciência Jurídica, que busca e proporciona a viabilidade e o entendimento do Direito dentro de uma disciplina de convivência humanizada, tornando-o uma nova possibilidade para a adequação do comportamento humano, não pela coerção, mas pela conscientização através das ordens sistêmicas efetivando uma melhor dinâmica da Justiça e o alívio dos jurisdicionados. [...] A proposta do Direito Sistêmico, é passar a uma nova fase do Direito: sem julgamentos e com maior efetividade aos jurisdicionados pela tomada de consciência e responsabilização deles mesmos (de cada parte) pelas escolhas ao passo de considerar o Direito como uma ordenação complexa da vida e convivência humana. (BADALOTTI, 2018, n.p)

Portanto, o Direito Sistêmico pressupõe que o Direito somente cumpre com sua função social quando efetivamente pacifica e reequilibra os desequilíbrios (sistemas) que lhe são provocados a resolver. Segundo Madaleno (2017), a visão sistêmica do Direito possui como fortes expoentes Bert Hellinger, sintetizador da utilização das Constelações Sistêmicas Familiares, e Ludwig Von Bertalanffy, criador da Teoria dos Sistemas.

De maneira que a penetração das ideias trazidas por esses (e outros) autores no mundo jurídico modificou, sobretudo, a forma como os conflitos passaram a ser vistos. Possibilitou 
transformar a maneira tradicional com que se conduz e trabalha o fenômeno que é a força motriz para o exercício de qualquer profissão na área jurídica: os conflitos. Justamente se se considerar que leis, jurisprudências, atos administrativos e etc., só são criados/provocados/motivados quando surgem "pretensões resistidas".

Logo, os conflitos deixam de ser observados como uma forma de indicar "os que têm razão" e os "que não têm", para serem compreendidos como um fenômeno que desperta diversos pontos de vista (MADALENO, 2017). Então, retira-se o enfoque da culpa - dos acertos e erros - para uma forma de reconhecer os ruídos, identificar contextos e padrões nas relações, tentando se (re)equilibrar o que está em desarmonia.

Nesse panorama é que emerge estudos visando uma nova forma de atuação daqueles que trabalham com o Direito: como o modelo de gestão da advocacia sistêmica ${ }^{4}$, o qual, sinteticamente falando, diz respeito ao despertar de competências tansversais pelos advogados. Isto é, habilidades e conhecimentos não específicos do Direito (não jurídicos), como competências relacionais, sensoriais e técnicas pelos advogados.

De maneira que essa construção começa por uma transformação desse profissional. Parte-se de um novo olhar do advogado para si, para o seu ofício, para a forma com que lida: com seus clientes (e partes adversas), com o seu escritório, com a comunidade e com os processos em que atua. Em outras palavras, trata-se de uma nova forma de perceber todos os sistemas conectados ao advogado e sua profissão. Rompendo-se com a cultura de olhar apenas partes do todo.

De acordo com a idealizadora desse modelo de gestão, a advocacia sistêmica tem como bases metodológicas abordagens de: psicologia positiva, neuro-semântica, programação neurolinguística, coaching sistêmico, consultoria sistêmica, points of you e constelações familiares e organizacionais (SANTOS, 2018, n.p). Além disso, não é um modelo fechado, pois está em construção, já que propõe o desenvolvimento contínuo de competências essenciais dos advogados, tais como: não julgar; pensar em possibilidades (geração de opções); desenvolver a escuta ativa; identificar perfis comportamentais; estabelecer rapport ${ }^{5} \mathrm{e}$ bases para o diálogo; elaborar perguntas de expansão de consciência; ter um olhar empático em todos os sistemas envolvidos por aquele conflito e etc. (SANTOS, 2018, n.p).

\footnotetext{
4 Fundado e desenvolvido por Marcella Santos Souza - vide $<$ https://www.gestaodaadvocaciasistemica.com.br/empresa $>$.

${ }^{5} \mathrm{O}$ rapport compreende constituir uma relação de confiança, conexão e sintonia com o cliente.
} 
Portanto, se distancia do senso comum de atrelamento da visão sistêmica a utilização das constelações familiares. Em realidade, as constelações familiares são uma das ferramentas base do paradigma sistêmico aplicado ao Direito. A própria origem das constelações sistêmicas por Bert Hellinger não remonta a um viés Jurídico, mas terapêutico, sendo que o uso delas no âmbito jurídico se deu apenas com o Magistrado Sami Storch, o qual foi o propulsor da aplicação da terapia sistêmica da constelação familiar por parte do Poder Judiciário, no Brasil.

Entretanto, não se pode negar que foram as constelações que deram a visibilidade para o pensamento sistêmico. E para que efetivamente a questão da justiça multiportas ${ }^{6}$ passasse a minimamente funcionar como método de condução de conflitos, especificamente falando do Poder Judiciário, na medida em que este passou a usar outras portas - "menos comuns" e normalizadas - de acordo com as especificidades das demandas.

Assim, com o modelo de gestão da advocacia sistêmica, o atendimento sistêmico passa a ser ancorado na consciência do todo, na análise estruturada da linguagem verbal e nãoverbal do cliente (CARVALHO, 2018, p. 54). De forma que o objetivo é que ao desenvolver essas habilidades: "o advogado facilite a ampliação de consciência de seus clientes, convidando-os a percepção ou visualização sistêmica dos contextos, relações, padrões, processos e origem do conflito" (SANTOS, 2018, n.p).

Como bem afirma Badalotti (2018, n.p), o advogado trata com a complexidade humana e, assim, já numa primeira conversa com o cliente pode fazer uso de técnicas retóricas dos saberes sistêmicos:

Frases e perguntas que proporcionem algum tipo de conscientização do cliente especialmente diante das possibilidades a serem elegidas numa demanda judicial e suas consequências. Por exemplo, normalmente, um cliente busca um advogado já colerizado e com olhar somente ao que lhe fere. Assim, pela conversa sistêmica pode-se viabilizar um alargamento da visão do cliente para bem enxergar a sua participação no evento que lhe leva à busca do Judiciário. (BADALOTTI, 2018, n.p)

No entanto, o modelo de gestão proposto pela advocacia sistêmica ratifica que antes de qualquer qualidade ou competência, esse profissional é um advogado, isto é, um defensor dos direitos do cliente. Por conseguinte, não é um mediador, um conciliador, um constelador ou

\footnotetext{
6 "Esta organização judiciária, proposta pelo Fórum de Múltiplas Portas (FMP), compõe-se de uma visão do Poder Judiciário como um centro de resolução de disputas, proporcionando a escolha de diferentes processos para cada caso, baseando-se na premissa de que existem vantagens e desvantagens em cada procedimento que devem ser consideradas em função das características específicas de cada conflito. Assim, em vez de existir uma única "porta" (o processo judicial) que conduz à sala de audiência, o FMP trata de um sistema amplo com vários tipos distintos de processo que forma um "centro de justiça", organizado pelo Estado (e apoiado pela iniciativa privada), no qual as partes podem ser direcionadas ao processo mais adequado a cada disputa". (CONSELHO NACIONAL DE JUSTIÇA, 2016, p. 18).
} 
um terapeuta. Não busca unir ou reconciliar as partes, tampouco evitar brigas. Trata-se de um advogado, mas que, por possuir uma concepção sistêmica, não inflama conflitos, evita dar conselhos além dos jurídicos e mostra a realidade advinda com o ajuizamento de um processo, por exemplo.

Portanto, significa um profissional que não entra no piloto automático daquela advocacia que enquadra casos a normas, sem grandes indagações ou provocações, limitandose a simplesmente isso. E sim uma advocacia que passa a oferecer presença em seu ofício, analisando o todo, identificando os padrões e as conexões oriundas do conflito exposto pelo cliente. E, nesse sentido, inclusive reconhecendo se o cliente está preparado para realmente perceber e conduzir o conflito a partir dessas conexões.

Deste modo, mesmo que judicializar seja necessário, a proposta é que durante o caminho do processo, este advogado o conduza de forma sistêmica - olhando para os contextos, atentando para a sua linguagem, sua postura durante esse caminho e etc. Por conseguinte, o objetivo não é extinguir com o tradicional, o cartesiano, o positivado.

Pelo contrário, isso seria ir de encontro ao que propaga e constitui esse modelo, pois, segundo as leis sistêmicas de Bert Hellinger (2007), o que vem antes, prefere e pertence. Significa reconhecer a coexistência não só desses paradigmas, mas do pertencimento desses profissionais a um sistema maior, que é o Judiciário, por exemplo, cuja ordem é que o Direito Positivista (ortodoxo, cartesiano, monista, etc.) precede ao Direito Sistêmico e, por isso, “o equilíbrio se dá na medida da aplicação e soma de um e outro adequadamente" (BADALOTTI, 2018, n.p).

Nesse sentido, a visão sistêmica desenvolve um olhar mais humano para as relações que o Direito tutela, na medida em que não só enxerga leis e ditames descumpridos em conflitos judicializados ou não. Mas sim pessoas, conexões e como efetivamente solucionálos, materializando um dos mais básicos dos direitos humanos: o acesso à justiça.

De acordo com Mauro Cappelletti e Bryant Garth (1988, p. 12), o acesso à justiça pode ser interpretado sob diferentes perspectivas, na medida em que sofre variações de extensão e sentido, pois depende do conceito de justiça adotado. Como se compreende que acesso à justiça não é sinônimo de judicialização, se questiona e critica a concepção excessivamente formalista e dogmática do Direito e a perspectiva unidimensional da Justiça (heterocompositiva),

Por essas razões é que se afirma que o pensamento sistêmico aplicado à advocacia auxilia na materialização do acesso integral (material) à justiça. Eis que ultrapassa a vertente formal do acesso a esse direito porquanto se trata de um paradigma pautado na preocupação 
em se configurar valores e fundamentos éticos de equidade e igualdade na administração dos conflitos, especialmente no que tange a esfera de atuação do advogado.

Goretti (2016, p. 67) afirma que o sentido integral do direito de acesso à justiça compreende a plenitude de sua dimensão social, jurídica e política, pois designa o direito de acesso a informação, a orientação jurídica, os meios alternativos de solução de conflitos. Por isso, elenca três razões fundamentais da adequação do sentido integral do acesso:

\begin{abstract}
Em primeiro lugar, por representar a plenitude da dimensão social, jurídica e política do direito fundamental em comento. Em segundo, por se revelar alinhado com um ideal democrático de reivindicação de direitos por vias plurais de prevenção e resolução de conflitos. Finalmente, em terceiro lugar, por compreender a possibilidade de realização de resultados justos por diferentes vias de prevenção e resolução de conflitos: as processuais e as alternativas ao processo (GORETII, 2016, p. 67/68).
\end{abstract}

De tal modo, considerando que o advogado é o filtro e o propulsor de todas as atividades judiciais, ao transformar o seu modus operandi, está-se alinhando com o sentido integral do direito de acesso à justiça. Não só porque é o advogado a chave para abrir a porta a esse acesso, mas porque, com o atendimento sistêmico, se torna uma chave mais humana, mais empática e que de fato cumpre com a sua função social.

Portanto, afirma-se que o pensamento sistêmico pode ser uma ferramenta de ressignificação da advocacia. Ressignificar é dar um novo sentido a algo. Nesse caso, o paradigma sistêmico aplicado a advocacia auxilia na retomada de propósito e na conversão de olhar desse profissional em sua forma de lidar e enxergar todas as conexões e fenômenos da vida próprios da dimensão jurídica.

Nesse caso, ressignifica essa profissão sob três vieses: estratégico, humanizado e consensual, na medida em que ambiciona ser um novo modo de exercê-la. Deste modo, de acordo com Santos (2018, n.p), é estratégico, pois centrado nas competências relacionais do advogado e no uso da visualização sistêmica; é humanizado, porquanto conecta, torna a relação cliente-advogado e também a processual mais humana, na medida em que enxerga em seu cliente um ser humano integral - composto de mente, corpo, emoção, comportamento e espírito -, com seus contextos e relações com todos os envolvidos no conflito; e consensual porque prioriza a reconstrução do diálogo e o uso dos meios adequados de solução de conflitos.

\title{
5. Conclusões
}


Este artigo objetivou um estudo que não se limitasse a criticar o contexto jurídico atual, cingindo-se a desconstruir o sistema posto. E sim apresentar um modelo para construílo sob novas bases, propondo-se iniciar por aqueles que, geralmente, são os primeiros profissionais chamados a agir. Aqueles que impulsionam, ajuízam e movimentam os processos: os advogados.

O paradigma sistêmico aplicado a advocacia pensa o Direito de forma mais ampla e respeita as especificidades dos contextos e relações. Nesse sentido, o modelo de gestão da advocacia sistêmica emerge ancorado em premissas como a de que cada indivíduo deve responsabilizar-se por si e, consequentemente, tomar suas próprias decisões acerca de seus conflitos.

De modo que os advogados podem auxiliar na expansão de consciência de seus clientes e na condução desses conflitos. Por isso é que se argumenta que o paradigma sistêmico aplicado a advocacia é uma tanto uma ferramenta de retomada de propósito como de ressignificação dessa profissão.

\section{Referências}

ALMEIDA, Diogo A. Rezende de; PAIVA, Fernanda. "Dinâmica da mediação: atores". In: Mediação de conflitos: para iniciantes, praticantes e docentes. Coordenado por Tania Ameida, Samantha Pelajo e Eva Jonathan. Salvador: JusPodivm, 2016.

AUN, Juliana Gontijo. Apresentação. In: VASCONCELLOS, Maria José Esteves de. Pensamento Sistêmico: o novo paradigma da ciência. $10^{\mathrm{a}}$ ed. rev. e atual. Campinas, SP: Papirus, 2013.

BADALOTTI, Damaris. Direito sistêmico: contribuições para o exercício da advocacia. In: Âmbito Jurídico, Rio Grande, XXI, n. 171, abr 2018. Disponível em < <http://www.ambitojuridico.com.br/site/?n_link=revista_artigos_leitura\&artigo_id=20389\&revista_caderno=15>. Acesso em nov 2018.

BARREIROS, Lorena Miranda Santos. Fundamentos constitucionais do modelo processual cooperativo no direito brasileiro. 2011. 237 f. Tese (Doutorado em Direito) - Programa de Pós-Graduação em Direito da Universidade Federal da Bahia. Salvador, 2011. Disponível em <https://repositorio.ufba.br/ri/bitstream/ri/10725/1/Lorena.pdf>. Acesso em 27 de junho de 2017.

CAPRA, Fritjof. A visão sistêmica da vida: uma concepção unificada e suas implicações filosóficas, políticas, sociais e econômicas. Tradução Mayra Teruya Eichemberg, Newton Roberval Eichemberg. São Paulo: Cultrix, 2014.

CAPPELLETTI, Mauro; GARTH, Bryant. Acesso à justiça. Porto Alegre: Fabris, 1988. 
CARVALHO, Bianca Pizzatto. Constelações familiares na Advocacia Sistêmica: uma prática humanizada. Joinville, SC: Manuscritos Editora, 2018.

CONSELHO NACIONAL DE JUSTIÇA. Manual de Mediação Judicial - de acordo com Lei 13.140/2015 (Lei de Mediação), a Lei 13.105/2015 (Novo Código de Processo Civil) e a Emenda 2 da Resolução 125/10. $6^{\mathrm{a}}$ ed. Organizado por André Gomma de Azevedo. Brasília: Ministério da Justiça e Programa das Nações Unidas para o Desenvolvimento, 2016.

GORETTI, Ricardo. Mediação e Acesso à Justiça. Salvador: JusPodivm, 2016.

HELLINGER, Bert; HÖVEL, Gabriele Ten. Constelações familiares: o reconhecimento das ordens do amor. Tradução de Eoisa Giancoli Tironi, Tsuyuko Jinno-Spelter. São Paulo: Cultrix, 2007.

MADALENO, Ana Carolina Carpes. Direito Sistêmico - um novo paradigma. Disponível em $<$ https://docs.wixstatic.com/ugd/1695f9_9851007e287f4904bbcae6e689b87f9e.pdf>. Acesso em 05 de outubro de 2018.

PELLEGRINI, Carolina Portella. SIMIONI, Fabiane. "A crise da jurisdição no estado moderno, o novo Código de Processo Civil e o marco legal da mediação". Juris, Revista da Faculdade de Direito, Rio Grande, v 23, p. 123-139, 2015.

SANTOS, Marcella. Advocacia Sistêmica - Exercício estratégico, humanizado e consensual. Disponível em < https://blog.sajadv.com.br/advocacia-sistemica/>. Acesso em 05 de outubro de 2018.

SILVEIRA, Simone de Biazzi Ávila Batista da. - Considerações sobre os conflitos familiares e a mediação como propostall. In: JURIS - Revista do Departamento de Ciências Jurídicas. v 11. Rio Grande: Editora FURG, 2005.

VASCONCELlOS, Maria José Esteves de. Pensamento Sistêmico: o novo paradigma da ciência. $10^{\mathrm{a}}$ ed. rev. e atual. Campinas, SP: Papirus, 2013. 